\title{
BMJ Open Finding 'the inner drive' for a rehabilitation process: a small-scale qualitative investigation among male patients with primary glioma
}

\author{
Mette Lysdahl Fahrenholtz, ${ }^{1}$ Anders Hansen (D) , ${ }^{2,3}$ Karen Søgaard (D) ,2,3 \\ Lotte Nygaard Andersen ${ }^{3}$
}

To cite: Fahrenholtz ML, Hansen A, Søgaard K, et al. Finding 'the inner drive' for a rehabilitation process: a smallscale qualitative investigation among male patients with primary glioma. BMJ Open 2019;9:e031665. doi:10.1136/ bmjopen-2019-031665

- Prepublication history for this paper is available online. To view these files, please visit the journal online (http://dx.doi. org/10.1136/bmjopen-2019031665).

Received 14 May 2019 Revised 12 November 2019 Accepted 13 November 2019

Check for updates

(C) Author(s) (or their employer(s)) 2019. Re-use permitted under CC BY-NC. No commercial re-use. See rights and permissions. Published by BMJ.

${ }^{1}$ Department of Psychology, University of Southern Denmark, Odense, Denmark

${ }^{2}$ Clinical Research, University Hospital of Odense, Odense, Denmark

${ }^{3}$ Sports Science and Clinical Biomechanics, University of Southern Denmark, Odense, Denmark

Correspondence to

Anders Hansen;

anders.hansen@rsyd.dk

\section{ABSTRACT}

Objective Brain tumours are relatively rare but hold a significant place in cancer rehabilitation due to their pronounced disabling capacity to promote physical, cognitive and psychosocial sequelae. This small-scale qualitative study used coping and motivational theories to gain understanding and knowledge of patients' experience of being diagnosed with a severe disease and of their view of a rehabilitation process.

Design Qualitative interview study.

Setting Odense University Hospital, Denmark.

Informants Five patients (men, aged 30-79 years) with primary glioma who had participated in a rehabilitation intervention.

Methods Semi-structured interviews were conducted. The phenomenological interpretive analysis was used to analyse the interviews.

Results The analysis revealed three main themes: (1) coping with a new life situation, (2) motivating and maintaining elements and (3) experience of the benefit of the rehabilitation programme.

Conclusion The study concluded that interviewed informants use problem-solving coping strategies, which make them more active in their health behaviour. However, passive and emotion-focused strategies related to confronting diagnosis may be used in some cases. The motivational aspect is multifaceted. Personal and interpersonal elements alongside a competitive setting are crucial to self-efficacy and benefit. The intervention's impact on health-related quality of life also has the potential to increase patients' resources to manage their situation.

Trial registration number NCT02221986

\section{INTRODUCTION}

Despite being relatively rare, brain tumours hold a significant place in cancer rehabilitation due to their pronounced disabling capacity to promote physical, cognitive and psychosocial sequelae. ${ }^{1}$ Glial-cell brain tumours (glioma) are among the most common and disabling brain tumours. On the basis of histology and clinical criteria, they are classified by WHO into grade I-IV tumours. ${ }^{2}$ Grade I gliomas
Strengths and limitations of this study

- This qualitative study fills a gap in the research literature, providing the patient's perspective on the complexity of cancer rehabilitation.

- Only men are included as informants, which raises the question of whether the findings can be extended to women.

- There may be gender differences in how patients handle their life situation.

- The phenomenological design provides healthcare professionals with an in-depth insight into the patient's world and provides greater understanding of patients' experiences of rehabilitation.

are generally benign and curable with radical surgical resection. ${ }^{3}$ They occur primarily in children and are somewhat distinct from grade II-IV, which mainly affect adults. Highgrade gliomas (III/IV) are the most common glioma subtypes and hold a bleak prognosis. ${ }^{4}$ Except for the significant differences in treatments and prognoses among benign and malignant gliomas, all patients with gliomas have to cope with a new life situation. The healthiest patients (grade I/II) face a chronic illness requiring follow-up assessments for their entire life, whereas the most affected patients (III/IV) have a short life expectancy and may be unable to care for themselves.

A systematic review by Ford et $a \tilde{l}$ concluded that patients with glioma often experience impairments in cognition either as a result of the tumour itself, or of the following surgery, radiotherapy or chemotherapy. Reduced cognition may interfere with memory function, understanding and decision-making and is associated with depression, fatigue, lower quality of life, sleep disturbance and poorer physical performance. ${ }^{5}$

Brain tumours are among the most challenging areas in neurological and oncological 
rehabilitation, ${ }^{6}$ because of the severe brain tissue damage and the significant adverse effects resulting from treatment. ${ }^{7}$ Research suggests that rehabilitation interventions may reduce the symptom burden and prevents or delays regression in patient function. ${ }^{6}$ Optimising the rehabilitation process of these patients is, therefore, of primary clinical importance.

There seems to be a tendency in the existing literature to use quantitative methods to examine rehabilitation for this patient group. A recent literature review pointed out that only one out of the nine identified studies used a qualitative approach ${ }^{8}$. The tendency in using quantitative methods, however, do not give a comprehensive picture of the complexity of the rehabilitation and underlying mechanisms, as patients' experiences have so far not been thoroughly investigated. A qualitative study by Midtgaard et at ${ }^{\ominus}$ suggests that cancer survivors experience their participation in similar rehabilitation as a means to achieve physical, social and mental well-being.

This study aims to gain an understanding and to generate knowledge of how patients recently diagnosed with a life-threatening disease experience the rehabilitation process by using coping and motivational theories. The study employs a phenomenological qualitative research method, since knowledge produced using a phenomenological design may provide healthcare professionals with an insight into the patients' lifeworld. ${ }^{10}$ The results of this small-scale study may support health professionals by providing a better understanding of patients' experiences of rehabilitation and may, therefore, help optimise those services for patients.

\section{METHOD}

\section{Study design}

This small-scale study used a qualitative phenomenological design with semi-structured interviews of patients with newly diagnosed primary glioma attending a rehabilitation intervention. By using the qualitative approach it is possible to obtain descriptions and an in-depth understanding of the informants' everyday life and the challenges they face. ${ }^{11}$ The authors have followed the Standards for Reporting Qualitative Research (SRQR). ${ }^{12}$

This qualitative study was embedded within the intervention group of a randomised controlled trial (RCT) evaluating the effectiveness of rehabilitation efforts in patients newly diagnosed with primary glioma.

\section{PATIENT AND PUBLIC INVOLVEMENT}

Patients and the public were not involved in the design of this study.

\section{Setting and informants}

The informants were newly diagnosed with a primary glioma at Odense University Hospital (OUH) in Denmark. Informants were recruited by the lead investigator of the RCT. In this study, patients were selected using a purposeful strategy aimed at generating in-depth information and nuanced insights into their individual experiences of the rehabilitation process. ${ }^{13}{ }^{14}$ Inclusion criteria were that the informants had completed the rehabilitation intervention and could understand and speak Danish. All invited informants agreed to participate.

\section{Rehabilitation intervention}

The European Association of Neuro-Oncology recommends patients with brain tumours to engage in rehabilitation. ${ }^{15}$ Physical and occupational therapy are modalities frequently used in rehabilitation settings, as they help patients to optimise functioning to regain an independent and meaningful life. The intervention included 6 weeks of physical therapy in the period concurrent with the chemoradiation. The treatment placed strong emphasis on exercise (cardiovascular training, resistance training and interventions individually designed to match patients' deficits or impairments) and took place in groups of up to four patients at a time. The programme also included testing for the self-perception of performance in everyday living. If a patient identified difficulties, a client-centred occupational therapy intervention (individual and goal-orientated) was incorporated as a part of the rehabilitation intervention. The evidence behind the content of the RCT intervention has been published in two papers. ${ }^{1617}$

\section{Interviews}

The first author conducted five semi-structured interviews on male patients aged between 30 and 79 years (table 1 ). The first author is a woman who has the practical training

Table 1 Participant information

\begin{tabular}{llll}
\hline Name & $\begin{array}{l}\text { Age group } \\
\text { (years) }\end{array}$ & Social status & Year of diagnosis \\
\hline Paul & $60-69$ & Married, adult children, actively working until diagnosis & 2015 \\
Henry & $50-59$ & Married, adult children, actively working until diagnosis & 2015 \\
Nick & $70-79$ & Married, adult children, retired & 2015 \\
Simon & $50-59$ & Married, children living at home, actively working until diagnosis & 2014 \\
Richard & $30-39$ & Married, children living at home, actively working until diagnosis & 2015 \\
\hline
\end{tabular}


Table 2 Semi-structured interview guide

Themes Interview questions

Expectations and motivation for rehabilitation

How did you get started on the training course?

Initially, did you think it was a good idea to start?

Why did you agree to participate?

Experience of participation in rehabilitation

How would you describe a typical day with the training course? What are your impressions of the training course?

How did you experience the intensity of the training?

Do you typically look forward to attending the training course?

Patient involvement

How has the content of the training course been decided?

Have you had preferences for specific training elements?

Do you feel you have been involved in decisions about training elements?

What does it mean to you to be involved in decisions about the specific training elements?

Experience of relations to health professionals and other participants during rehabilitation

Do you train on your own or in a group?

Do you have a preference for training alone or in a group?

(What was your experience of the other participants?)

How will you describe your relations to the health professional in charge of the training?

How has this relationship impacted on the training course?

Experience of changes resulting from the rehabilitation

Have you experienced any changes in health or well-being since you started rehabilitation? Will you describe an example? How are you getting on with your training now?

Do you still today make use of what you have learnt during the training course?

Overall evaluation

Overall, what have you experienced as the best part of the training course?

Overall, what have you experienced as a challenge when participating in the training course?

to perform interviews. No contact was made prior to the start of the study apart from a short telephone call.

The interviews were recorded and transcribed verbatim, and field notes were taken. The interviews took between 47 and $67 \mathrm{~min}$. The informants were given the option to read the transcript interviews on request.

Since patients with glioma can suffer from severe physical difficulties, which may affect their mobility in everyday life, the informants were given a choice to interview in their own home, at their workplace, in a room at $\mathrm{OUH}$ or as a telephone interview. Three of the informants chose to be interviewed at home, one at work and one at the hospital. Although given a choice, no informants decided to have a spouse or family member attending the interview.

\section{Interview guide}

The interviews were structured around an interview guide (table 2) with a phenomenological frame of reference and contained relevant themes and related interview questions formulated in everyday language, addressing the aim of the study. ${ }^{11}$ A pilot interview was conducted to refine the interview guide before use.

Each interview opened with a briefing about the objective and design of the study. The interviewer knew the interview guide well and asked the questions primarily in the format in which they were written, but sometimes, as a result of the natural flow of the conversation, informants might bring the themes up themselves unprompted. Words like 'rehabilitation' were not included in the questions to preserve openness to the phenomenon. Instead, the informants' choice of words was allowed to determine the lexical composition of the interview. To ensure broad descriptions, informants were asked to give and explain examples from their everyday life.

Questions were open-ended, and reflective listening was used to gain in-depth and nuanced descriptions from the informants. ${ }^{11}$ Reflexive listening was used with thoughtful consideration that permitted listening and reflection along the way, so that the interviewer was able to engage in a dialogue and ask further questions that could make the informants' descriptions rich and nuanced. Attempts were made to create a natural rhythm in the interview with connected themes, so the informants did not experience any abrupt leaps in topics.

\section{DATA ANALYSIS}

\section{Interpretive phenomenological analysis}

General guidelines for interpretive phenomenological analysis (IPA) were followed. ${ }^{18}$ This was used as a strictly phenomenological research approach ${ }^{10} 19$ to understand the mental processes behind the informants' lifeworld. We 
developed an interview guide focusing on our study aim, although during interviewing the interviewer was open, curious and reflexively listening to informants' descriptions of experiences to make sure that data contained detailed descriptions of the participants own experiences of the rehabilitation process. ${ }^{19}$

The transcripts were read, and initial descriptive notes, thoughts and associations were recorded. Themes in each transcript were identified and structured in a coding tree grouping main themes and minor themes. The outcome of the analysis was continuously discussed and negotiated between the first and last authors. The outcome of the analysis is described in the 'Results' section, and selected quotes are used as examples to give nuances and particularities and show the uniqueness of the informant. Interviews were conducted in Danish, and the quotations used in the results section were translated into English by a professional translator. All participant names are pseudonyms.

\section{Theoretical framework}

A theoretical framework was applied that adopts a coping and motivational perspective. Results from the analysis will be compared and discussed, and this theoretical framework will be used to develop a new understanding of the patient's rehabilitation process. ${ }^{14} 19$

Lazarus $^{20}$ describes coping as a cognitive behaviour process deriving from a contextual transaction between human and environment. There are different ways of coping with stressful situations, and Lazarus and Folkmann $^{21}$ suggested two types of coping strategies: emotionfocused coping and problem-focused coping.

The motivation for participation will be understood as follows:

The term motivation refers to factors that activate, direct, and sustain goal-directed behaviour (...) Motives are the 'whys' of behaviour-the needs or wants that drive behaviour and explain what we do. We don't actually observe a motive; rather, we infer that one exists based on the behaviour we observe. ${ }^{22}$

Both the Health Belief Model (HBM) and SelfDetermination Theory (SDT) will be applied to develop specific and nuanced knowledge and understanding about elements of motivation for participation in the rehabilitation intervention. In continuation of this, the concept of self-efficacy is important because patients' motivation and capability to act and perform a health-related behaviour is dependent on patients' belief in their own capacity. In addition, the informants' perceived and experienced benefits from participation in the programme are interlinked with motivation and health-related behaviour. ${ }^{23}$

\section{RESULTS}

The analysis identified three main themes: (1) coping with a new life situation, (2) motivating and maintaining elements and (3) the experienced benefit of the rehabilitation programme.

\section{Coping with a new life situation}

A shared experience for the informants was that they were in a completely new life situation with a long-term illness, even though they only felt subtle symptoms. Despite the severeness of his diagnosis, Richard explained how it had been challenging to identify himself as a sick person:

Yes, and I have felt reasonable ok, given what has happened, I'd say. So sometimes it has been hard to feel that you're ill.

Because of the sudden change in their lives, informants experienced acceptance of the diagnosis as a process that was long and difficult. One of the informants, Simon, talked about his sudden diagnosis and how he had almost regained full functioning:

So in 1 week, from having a totally normal daily life to having a long-term illness. I mean, just like that (snaps his fingers). And I didn't have a headache, I didn't have any form of, er, forewarning (...). And maybe that meant that I was more robust, rather if I'd gone and not really known what the problem was and run from pillar to post in the health system. It was just 'This is what's wrong with you. Get used to it'. (...) So it's not good getting all upset about that final two percent you can't manage, but, um, that's just how it is.

For Simon, it seemed that the brief process of clinical investigation he experienced made it easier to accept and cope with the diagnosis. Elsewhere in the interview, Simon attributed this to a resilience he had before the diagnosis. In his statement, there is also a recommendation that, as a patient with a brain tumour, you should accept that there are things that you can no longer do after surgery.

In coping with their new life situation, the informants regarded a well-functioning social network where they could seek emotional support as one of the most important elements. It had an impact on whether they had been able to get back on their feet and not descend into isolation despite their illness. Richard described this as a 'mental help':

Of course, I get a whole load of mental help at home from my network (...) We can talk openly about everything, and we can indulge in some real sob sessions. And that's something you have to do in all this. You can't go around being a caveman when you've got this, you really can't. You just have to, yes, you simply have to open up in all this.

For Richard, the emotional support of his network during the process was a necessity for being able to cope psychologically with his new living situation.

All informants stressed the importance of maintaining a 'normal everyday living', where illness is not an overshadowing element. Paul simply chose to be himself: 
I have simply chosen-I have just been myself (...) That's because I have been able to do what I have so wanted to do. It has been like I have had to wait for Ellen to come home before I could get the coffee made, or... peel the potatoes, or... I mean, I have just done the cooking like I usually do.

It seems that the choice to be one's self and to maintain the sense of self depends on the level of the patients' functioning and what they could manage in their everyday life.

Knowledge about the beneficial effect of physical exercise seemed to be an underlying element in the informants' stories:

Henry: So I was aware that I should take some exercise. And I had heard people say that exercise was good for the body and your recovery. So for me, it was pretty important to get started on some exercise.

This knowledge encouraged the informants to be action-oriented in their behaviour, and training took on increased value for them in their everyday lives compared with earlier. At the same time, the informants expressed their confidence in the physiotherapist's professional knowledge in the field, which gave them a feeling of security.

\section{Motivating and maintaining elements}

All informants talked about elements that they felt motivated and supported them in the rehabilitation process and acknowledged the importance of having a training agreement with other people involved.

Simon: The good thing about the training was, like, you have an agreement. And then you, like, get yourself out the door (...) I can't say it any other way than that when you've made an agreement, and no matter if it's for training or a walk, or whatever, like, it just helps.

The urge to keep an agreed appointment motivated the informants to come to training. The external conditions for the training were set, and that made the training a commitment that was hard to run away from.

Three of the five informants experienced the competitive element as an important element. Among these, a competitive approach helped them to make a 'game' out of the training. At the same time, the competition helped to ensure a high level of intensity, which improved results of the training. For example, Paul found that setting goals and achieving them motivated him:

A sporting element can easily find its way into it. Because you're battling with yourself a bit every day, of course (...) But all the time I have, I mean all the time I could keep it, cycle a bit faster, lift a bit more weight, push a little more. It became something of a goal, you know. I think it was something like that that motivated me.
Richard also set himself a personal challenge for a constant improvement, which he described as deriving from his 'inner drive':

Yes, I mean, all the time an inner drive like that, to make it be better, and to make it be better, and to make it be better (...) And I am also a bit of a competitive guy, so it went fast... You quickly discovered that you could bike faster and further and harder and so on. So, um, yes, it was very rewarding, and it gives you an experience of success, of course. So that was great at a time when you could easily imagine just hanging out at home and getting bored.

The quote shows that Richard experienced success as valuable for him because it prevented him from feeling bored at home.

A theme consistently brought up by all the informants was being pushed during training. The theme, however, was valued in very different ways by individual informants. For Nick, this aspect was the most challenging part of the process, but at the same time it helped him to generate the motivation for training:

Nick: And the most challenging thing is when, is... It's when they push you, you know. 'Now you're damn well going to...' Yeah, you do have to force yourself. And I have forced myself quite a bit, but now I have that energy.

Interviewer. Yes. What kind of push do you think, er, you get?

Nick: It's... That spark, it isn't there, and then you can't see it straight away.

When asked about the most challenging part of being pushed, he answered that it crossed his emotional boundaries to go beyond what feels like the maximum he could physically do. Other informants did not express any reason to push themselves unnecessarily since their bodies were fragile due to the illness and medical treatment. Others again felt that it was not so much a physical boundary as a psychological one that needed to be transcended through a process of recognition:

Richard: But I quickly came to feel that nothing happened as a result, that it wasn't dangerous. When you've just had your head cut open, you think 'Oh no, this is dangerous, I need to be careful, I mustn't do too much, just think if the wound opened, if something happened.' But it doesn't. And that, too, is part of the process of recognition, that all that business about not actually needing to take as much care as you think, you have to, because, of course, you're shit scared when someone starts to mess about inside your head.

Another area where the informants had slightly contradictory statements was on the group make-up. For some informants, it was not important to be in a group, as they did not feel the need to be social during the training, as 
other people in their network met the need for social contact. Others, on the other hand, felt that socialising was the thing that motivated them. Simon described the company of like-minded people as his incentive:

But there needs to be a carrot in all this, and that is the fact that you are together with like-minded people (...) So it was like we could use each other to spar with as regards the challenges that you face when you suddenly get a diagnosis, and yes, to find a new daily rhythm, you know, and to work out what I need to do, what I can do, what I am allowed to do and how we can solve these various things.

According to Simon, the group became a direct catalyst for optimising training compliance and at the same time, allowed each of them to find social support in their new life situation. Group training allowed patients to mirror themselves in others. However, the functional level of the group must be similar, since patients with a weaker level of functioning seem to be demotivating:

Richard: You get to think about how things might have been. It could have been, yes, it could have been a death sentence, but that's not what it is, for me. But yes, it's very individual, isn't it? Do you get more energy by looking at people who are in a really bad way? I don't believe so.

Four of the informants emphasised the importance of a professional yet friendly relationship with the healthcare professionals. Continuous good contact with healthcare professionals can thus help create a strong working alliance between the patient and the healthcare professional.

\section{The experienced benefit of the rehabilitation programme}

All the informants were aware of the benefits they experienced during and after the rehabilitation process as they achieved better physical condition, which was measured by various physiotherapeutic tests. The most important thing for Henry, however, was not the results on the tests but the recovered motivation he found in exercise:

Then I also finished off with a kind of analysis of how good my physical form was. Some really specific tests. And there was a long questionnaire about... About all sorts of stuff (...) And there was also a marked improvement from the first time. But the most important thing, it has done such a lot for my everyday life as regards doing more training.

For Nick, however, it was not so much a matter of physical form and pleasure in training, but more about the things that have become easier for him in his everyday life:

I could feel day by day, more or less, how my process-I could do more and more. And Susanne (his wife) could see it to some extent, when we sat eating when I had to reach out for something or other... At the start, yes, I reached past things and couldn't concentrate at all.
The experience of improved levels of functioning seemed to be an important benefit for the informants. There was also a broad consensus that they would not have come so far without the rehabilitation programme, which helped them to structure the training and reminded them that it was possible to achieve better results.

However, the training also had a psychological impact that for most was felt to be the most important benefit. Three informants described how the medical treatment became more natural to cope with, as they had something to look forward to. The exercise seemed to increase the experience of joy before and after the training. Additionally, the exercise gave them a sense of well-being. For example, Simon said that he got the feeling that the body was being cleansed of chemicals from the medical treatment:

And coming outside and getting some fresh air, er, just does something or other. And I am utterly convinced that doing something physical, to get a sweat up at the same time as receiving chemo, yes, you smell of one big chemical factory, of that special, at the end of the treatment. And it can only be good for your body to get rid of those waste products from those chemicals (...) So even if it didn't do anything else, it was good for your head and to do something and to be together with some others.

Some informants described being bothered by not being able to do as much in their daily lives as they could before the illness. It caused negative thoughts about themselves and feelings of guilt towards the family. About this, Richard said:

The feeling you get in your body is, you know, at least it has for me, been the best thing (...) The first month after the operation I was just half a vegetable, you know? Then you just lie there and are mega, mega tired and are overcome by your bad conscience, because from 1 day to the next you can't be the super-dad you were before. Those bad thoughts that career round in your head. But, er, when you get on with it and are challenged a bit, and your body starts working.

It indicates that, for Richard, the training reduced his automatic negative thoughts because his thought pattern was broken and replaced with something more meaningful. Following this, he said that one of the side effects of the medical treatment was his difficulty in sleeping. However, the training gave him natural tiredness that helped maintain a better daily rhythm.

The informants reported that the functioning and sense of well-being that the exercise provided resulted in what they described as increased quality of life:

Then I really felt that I... Nah, it may be wrong to say that I felt myself to be a new person, but it's true, I did really feel that something happened when I was up and training (...) I'll start getting a bit philosophical now, but if your quality of life and joy in life are 
increased, and that happens by taking exercise, well, then you have to be better in every possible way at getting through it. I don't know, and extending your life, or, surviving, you know?

Overall, the rehabilitation process can help to shift the focus away from the illness, promote better mood and increase the perceived energy, which can help the patients to experience improved quality of life during and after the rehabilitation process. The increased quality of life may also have a preventive effect, as it helps to create better resources to cope with the subsequent course of the illness.

\section{DISCUSSION}

A theoretical framework adopting both a coping and motivational perspective will be applied to develop the discussion of the patient's rehabilitation process. Existing scientific literature will also be included in the discussion where relevant. The study's methodological considerations and limitations will be outlined and, finally, its conlusions summarised.

\section{Coping with the new life situation}

From the study, it is clear that informants are experiencing their changed life situation as chaotic. The informants describe it is hard to identify themselves as being ill, as there may have been no disease symptoms before, and because their level of functioning has remained relatively unaltered. This finding is consistent with the findings of a study by Sterckx et $a l,{ }^{24}$ where the informants describe the experience of the diagnosis as being unreal. It is also seen that informants' lack of identification with being ill can be due to the abruptness of the course of illness. In both studies, the symptoms may be perceived to be subtle, which is in contrast to the severity of the disease. According to HBM, the conflict between the cognitive perception of a severe health threat and the lack of identification with their illness may lead to a health behaviour that can provide a feeling of control with their situation. ${ }^{2325}$

It suggests that through cognitive processing, they have evaluated the stressful situation as being of significance to their lives. ${ }^{20}$ Seen from a coping perspective, the cognitive assessment of the new life situation has an impact on how informants choose to deal with the situation. ${ }^{20}$ The coping style depends on whether they have assessed that they have the resources to act on the stressor. Lazarus' theory $^{20}$ thus means that the informants either use an emotion-focused or a problem-solving coping style when dealing with the new life situation. However, the findings in this study indicate that the informants made use of both coping strategies at the same time. On one hand, they use emotion-focused coping in dealing with the difficult emotions associated with receiving a severe diagnosis by, for instance, distancing themselves from the disease. On the other hand, this is also a problem-solving coping strategy, as the informants take an active decision not to let the disease affect their everyday lives, performing their activities as usual. The informants thus felt that they could handle the stressor with their resources, and the encouragement from health professionals to participate in the physical training may support this coping strategy.

One of the findings was that the informants' decision to participate in the rehabilitation process was based in part on the knowledge that exercise is beneficial to people in their situation. From an HBM perspective, this shows that the patients expect that their goals will be achieved.

As in the longitudinal study by Piil et $a l,{ }^{26}$ the present study identifies a proactive attitude on the part of the patients and an immediate need to engage themselves actively to optimise the effect of the standard oncological treatment in the form of surgery, radiotherapy and chemotherapy. The interviews in the present study also showed a link between proactive health behaviour and general psychological well-being.

\section{Motivating and maintaining elements}

For the informants, one of the essential elements in showing up to the training sessions was having an agreement whereby others depend on their presence. An explanation for this may be that the informants experience extrinsic motivation based on an external goal and a commitment to satisfy the other informants in the rehabilitation. Following the SDT, ${ }^{27}$ this can be interpreted to mean that they do not experience an intrinsic motivation for training. However, as explained by the same theory, it can also mean that the patients relate to the meaningful connection created between the parties involved in the rehabilitation. The group forms a relationship that allows the patients some sparring and reflection that they cannot achieve in their network. Social support in this situation has the character of coping with problemsolving since their action to seek support is actively aimed at their network.

Spending time with like-minded people can, at the same time trigger a sense of hopelessness. Therefore, the groups should be carefully compiled based on comparative levels of functioning and life situation. A heterogeneous group composition may be demotivating, as the desired sense of cohesion may be difficult to activate. Thus, the meaningful element in the relations is not achieved. The findings also show that the positive effects of the group are limited to the mutual relationships between the members and their participation in the rehabilitation. Herein lay the importance of the motivational and maintaining elements for the informants' experience of the benefit and effect of the rehabilitation. ${ }^{23}$

The social interaction with the healthcare professionals may help to meet the social needs of meaningful relationships while strengthening their working alliance during the rehabilitation. A part of the narrative thread of the interviews was that the staff helped to provide positive feedback during training, which may have increased the experience of success. According to SDT, this can be related to the informants' sense of competence, where a match is observed between the goals being set and their 
own experiences. It can be argued that this conformity may have helped to give the informants a sense of control.

Another aspect that relates to the informants' autonomy and competence is their feeling of being pushed by the healthcare professionals during training. Some informants felt that their body was fragile and weak, which erects a psychological barrier that can be transcended through a process of recognition. It can be related to the informants' self-efficacy and belief in their abilities. When this limit has been transcended and acknowledged, SDT would suggest that informants may feel freer to perform different actions during training. It indicates that the informants may have experienced a blockage about the learning process, where they acted on what they thought their body and mind could cope with. ${ }^{28}$ It is possible that patients' lack of self-efficacy may increase the risk that they cannot whole-heartedly perform an activity. It is also possible that this affects their motivation, as they may feel pressure to perform without having faith in their skills. ${ }^{29}$ It is possible that this finding is related to the patients' general use of coping strategy, which can be explained by other personality dispositions.

During the training, the informants' sense of being pressured is often accompanied by a competitive aspect. For some patients, competitiveness makes the exercise fun and intense, which mean that goals are continuously being achieved and self-efficacy upheld. It can, then, be described as a circular process in which intrinsic motivation is initially necessary to gain a successful experience, and this success experience further strengthens and maintains elements of intrinsic motivation during the rehabilitation process.

\section{The experienced benefit of the rehabilitation programme}

The improved physical functioning has been a significant experience. This finding is consistent with previous quantitative research, which has found similar rehabilitation courses to be effective in increasing patient functioning and participation in everyday life ${ }^{630}$ It is one thing that the improvements are measurable, but, according to this study, greater value is derived from the fact that the patients themselves experience a change. According to HBM, the perceived efficiency may be more dependent on the balance between the advantages and disadvantages of participation in the rehabilitation process towards their desired goals. It is critical for their motivation to engage in health behaviours demanded by the rehabilitation process and in the next course of treatment.

Furthermore, the findings of this study indicate that physical training has given the informants an increased body awareness. It is attributable to increased self-efficacy, as their actions are linked to the belief in their competencies. It indicates that increased self-efficacy is achieved by transcending mental barriers erected by their physical abilities. It is in line with the phenomenological approach of the lived body that the recognition above needs to be experienced physically to be understood mentally. The informants describe this process of transcendence and recognition of their limits and capabilities as being positive. For some, it may result in increased body awareness, while for others, especially at first, it may create a sense of discomfort. It is possible that previous activity levels affects this and that patients who have previously exercised at high-intensity levels have higher body awareness, allowing them to overcome their limits more quickly, with less sense of discomfort and have a higher self-efficacy.

The rehabilitation process had psychological benefits for all informants. In previous research, a variety of treatment procedures have been shown to cause adverse effects such as fatigue and headache, which may cause emotional distress. ${ }^{31}$ In the present treatment, on the other hand, energy levels are increased, because the exercise causes natural tiredness in the body that improves sleep and contributes to a natural daily rhythm. Accordingly, the informants described the feeling that their body had been 'purified' by the medical treatment both physically and mentally. It suggests that physical exercise may help reduce the experience of adverse effects, which is related to the medical treatment. This connection can thus be psychosomatic.

Only in a few situations did informants show signs of using passive emotion-focused coping strategies. An important finding here is that during the rehabilitation process did the informants derailed negative thoughts and tendencies to ruminate, which might have led to anxiety or depression. ${ }^{32}$ Physical exercise may help to prevent these affective disorders, which may impact their everyday life and have a bearing on health-related quality of life. ${ }^{33}$ The informants used phrases such as 'life value', 'energy level' and 'joy of life'. These terms reflect the definition of the more clinical and research-oriented concept of 'health-related quality of life'. ${ }^{34}$ Lazarus ${ }^{20}$ suggests that the way a person is coping can either create or ease distress. Improvement in health-related quality of life may help to increase the informants' resources in handling the subsequent course of the disease, as is described in a review by Graven and Grant. ${ }^{35}$

\section{Methodological reflections and limitations}

When examining patients with glioma, there is a special circumstance that they may have severe cognitive and personality deficits. This phenomenon may have affected the interviews. However, we consider that it had no implication for the understanding of the content and thereby did not affect the research value of the study.

The number of informants is relatively small due to time restrictions in the primary RCT, and, by coincidence, all patients present during the recruitment period were men. These two elements present the principal limitations of the study. Nevertheless, even with this small number of informants, the qualitative study design gathers important individual lived experiences from the informants. Our aim was never to arrive at an objective or generalised truth. The selected informants provided rich information for developing knowledge and understanding of the rehabilitation process, ${ }^{13} 14$ which is relevant for health professionals supporting the rehabilitation 
for patients with glioma. Even though no informants were women, conclusions may also prove to be transferable to women. It is a strength the results have been linked to theoretical concepts using a theoretical framework. ${ }^{14}$ When interviewing patients with life-threatening cancer, there may be a risk that the interviewer will cross the patient's boundaries by asking the informants to open up about their lives and by asking them to reflect on their vulnerable life situation and experiences. In this context, the consideration of the patients' interests was a vital part of the interview. The interviewer showed empathy and made a safe space in which patients could share their experiences. Kvale and Brinkmann ${ }^{11}$ discuss whether this type of relationship might potentially be unethical, as the interviewer can portray the relationship with the patients as a false friendship, leading patients to feel an obligation to open up and provide information that they will later regret. The interviewer was therefore aware of initiating a safe contact with the patients while at the same time being transparent about her role during and after the interview. Sivell $e t a l^{36}$ point out the ethical risk that conducting research with end-of-life patients may unintentionally become a therapeutic process for informants and that the researchers may feel that it is beyond the remit of their research role. However, when conducted by professionals who were aware of these potential risks, the interviews also give voices to a patient group that due to these concerns are seldom heard. The expected value for evidence-based clinical care clearly supports such carefully conducted interviews also being conducted among our most vulnerable patients.

Some cancer research suggests that there may be a gender difference in how patients handle a change of life situation. For example, Agger nd $\varnothing \operatorname{lgod}^{37}$ argue that men have a greater tendency than women to use problemsolving mechanisms in dealing with the cancer diagnosis. In practice, this can mean that men are more likely to opt for the rehabilitation programme than women. Therefore, it may be relevant to supplement the present study with a specific focus on women.

As previously described, most empirical studies are based on quantitative methods. Therefore, the present study fills a gap in the research literature in that it is methodologically designed to acknowledge and reveal the complexity of rehabilitation from the patient's perspective. ${ }^{11}$ The present study makes use of semi-structured interviews with a focus on the informant's thoughts, feelings and motivations for rehabilitation, and not their actual behaviour during the training. It may be considered a limitation of the present study and future studies may benefit from field surveys that include observation of multiple training sessions.

In cancer research, growing attention is given to the importance of improving quality of life as an intervention outcome. As has been described, patients experience a range of severe emotions that can lead to the development of affective disorders such as depression and anxiety. In line with Lang-Rollin and Berberich, ${ }^{38}$ the results of this study indicate that the need for psychological and psycho-oncological interventions is threefold and requires: a) social support from the professionals working with the patients, b) enhancement of the patients' resources, including their motivation and c) provision of specific psychological interventions. Psychological interventions may differ, depending on the primary issue. ${ }^{38}$ Patients in this study reported existential and spiritual distress, which could highlight a need for individual psychotherapy and mindfulness-based interventions. The mindfulness training could benefit from being group-based, as patients may derive advantages from being in a group with like-minded people.

\section{CONCLUSION}

This small-scale study among male patients with glioma, participating in an outpatient rehabilitation intervention identified how male patients use problem-solving coping strategies, which make them more active in their health behaviour. However, this strategy may be followed by passive and emotion-focused coping strategies related to challenges with self-identification when confronting the diagnosis. Both personal and interpersonal elements maintain patients' motivation for rehabilitation. Having an agreement for a training session whereby others are dependent on your presence is an important motivational element. Another element is a positive competitive setting that motivates patients to challenge their physical and psychological limits for high-intensity training leading to increased body awareness and self-efficacy. Health professionals should, however, be aware that challenges can be overwhelming when patients have a sense of their body as being fragile. The real benefit of their rehabilitation was found to lie in its social aspects. Informants build significant relations with health professionals and other patients in the rehabilitation group.

The improved health-related quality of life experienced by interviewed informants may have been affected by their characteristic use of coping. The improvement in healthrelated quality of life they experienced may boost resources available to patients to manage their new life situation in the future.

\section{Further research}

The use of 'mixed methods' offers a broader perspective on the phenomena of how the patients' with glioma experience the rehabilitation. ${ }^{39}$ For example, the themes from this study could form the basis of a quantitative survey to provide an overview of those themes in the rehabilitation process that most often occur among patients with glioma. This method can also clarify how many patients experience being pushed by healthcare professionals as a positive and whether their response is related to previous activity level and type.

Future research can also examine patients who have declined to participate in the rehabilitation process and those who served as controls in the RCT. It may be argued that the informants in the present study may well be among 
the more resourceful individuals, who make extensive use of active and action-oriented coping strategies, which are believed to have a positive effect on their health-related quality of life. In this context, it would be relevant to gain knowledge about the background for those patients who choose not to participate in rehabilitation. Furthermore, the present study clearly gives cause to reconsider a needs assessment for this particular patient group. Future research is called for to evaluate whether the important elements of social support and social interaction that help patients find 'the inner drive' to take part in a rehabilitation process could be formally integrated into the future rehabilitation offered to this patient group.

Contributors MLF, AH, KS and LNA conceived the presented idea. MLF performed the interviews. MLF took the lead in writing the manuscript. All authors have provided critical feedback and helped to shape the research, analysis and discussion of results, as well as contributed to and approved the final version.

Funding The authors have not declared a specific grant for this research from any funding agency in the public, commercial or not-for-profit sectors.

Competing interests None declared.

Patient consent for publication Not required.

Ethics approval The research protocol in the randomised controlled trial was approved by The Regional Committees on Health Research Ethics for Southern Denmark. According to Danish law, interview studies are exempt from ethical approval by the Regional Scientific Ethics Committee for Southern Denmark as it does not fall within the scope of the Medical Research Involving Human Subject Act $(\S 14,2$.$) . All informants gave informed written consent before the interview.$

Provenance and peer review Not commissioned; externally peer reviewed. Data availability statement № data are available.

Open access This is an open access article distributed in accordance with the Creative Commons Attribution Non Commercial (CC BY-NC 4.0) license, which permits others to distribute, remix, adapt, build upon this work non-commercially, and license their derivative works on different terms, provided the original work is properly cited, appropriate credit is given, any changes made indicated, and the use is non-commercial. See: http://creativecommons.org/licenses/by-nc/4.0/.

\section{ORCID iDs}

Anders Hansen http://orcid.org/0000-0002-5400-8847

Karen Søgaard http://orcid.org/0000-0003-3968-6364

\section{REFERENCES}

1 Lehmann JF, DeLisa JA, Warren CG, et al. Cancer rehabilitation: assessment of need, development, and evaluation of a model of care. Arch Phys Med Rehabil 1978;59:410-9.

2 Louis DN, Perry A, Reifenberger G, et al. The 2016 World Health organization classification of tumors of the central nervous system: a summary. Acta Neuropathol 2016;131:803-20.

3 Claus EB, Walsh KM, Wiencke JK, et al. Survival and low-grade glioma: the emergence of genetic information. Neurosurg Focus 2015;38:E6.

4 Ostrom QT, Gittleman H, Truitt G, et al. CBTRUS statistical report: primary brain and other central nervous system tumors diagnosed in the United States in 2011-2015. Neuro Oncol 2018;20:41-86.

5 Ford E, Catt S, Chalmers A, et al. Systematic review of supportive care needs in patients with primary malignant brain tumors. Neuro Oncol 2012;14:392-404.

6 Khan F, Amatya B, $\mathrm{Ng} \mathrm{L}$, et al. Multidisciplinary rehabilitation after primary brain tumour treatment. Cochrane Database Syst Rev 2013:CD009509.

7 Hansen A, Rosenbek Minet LK, Søgaard K, et al. The effect of an interdisciplinary rehabilitation intervention comparing HRQoL, symptom burden and physical function among patients with primary glioma: an RCT study protocol. BMJ Open 2014;4:e005490.

8 Piil K, Juhler M, Jakobsen $\mathrm{J}$, et al. Controlled rehabilitative and supportive care intervention trials in patients with high-grade gliomas and their caregivers: a systematic review. BMJ Support Palliat Care 2016:6:27-34.

9 Midtgaard J, Hammer NM, Andersen C, et al. Cancer survivors' experience of exercise-based cancer rehabilitation - a metasynthesis of qualitative research. Acta Oncol 2015;54:609-17.

10 Smith JA. Qualitative Psychology: A Practical Guide to Research Methods. SAGE Publications, 2015.

11 Kvale S, Brinkmann S. Interview: introduktion til et håndværk. Hans Reitzel, 2009.

12 O'Brien BC, Harris IB, Beckman TJ, et al. Standards for reporting qualitative research: a synthesis of recommendations. Acad Med 2017;89:1245-51.

13 Maxwell JA. Qualitative research design: An interactive approach. Thousand Oaks Calif: SAGE Publications, 2013.

14 Malterud K. Kvalitative forskningsmetoder for medisin og helsefag: en innføring. Universitetsforlaget, 2017.

15 Pace A, Dirven L, Koekkoek JAF, et al. European association for neuro-oncology (EANO) guidelines for palliative care in adults with glioma. Lancet Oncol 2017;18:e330-40.

16 Hansen A, Boll M, Minet L, et al. Novel occupational therapy intervention in the early rehabilitation of patients with brain tumours. British Journal of Occupational Therapy 2017;80:603-7.

17 Hansen A, Søgaard K, Minet LR. Development of an exercise intervention as part of rehabilitation in a glioblastoma multiforme survivor during irradiation treatment: a case report. Disabil Rehabil 2019;41:1608-14.

18 Coolican H. Introduction to Research Methods and Statistics in Psychology, 2009.

19 Smith B, Sparckes AC. Routledge Handbook of Qualitative Research in Sport and Exercise. Taylor \& Francis, 2016.

20 Lazarus RS. Coping theory and research: past, present, and future. Psychosom Med 1993;55:234-47.

21 Lazarus RS, Folkman S. Stress, appraisal, and coping. 1984.

22 Nevid JS. Psychology: concepts and applications. Belmont, CA: Wadsworth Cengage Learning, 2013.

23 Rosenstock IM, Strecher VJ, Becker MH. Social learning theory and the health belief model. Health Educ Q 1988;15:175-83.

24 Sterckx W, Coolbrandt A, Clement P, et al. Living with a high-grade glioma: a qualitative study of patients' experiences and care needs. Eur J Oncol Nurs 2015;19:383-90.

25 Redding C, Rossi J, Rossi S, et al. Health behavior models 2000.

26 Piil K, Jakobsen J, Christensen KB, et al. Needs and preferences among patients with high-grade glioma and their caregivers - A longitudinal mixed methods study. Eur J Cancer Care 2018;27:e12806.

27 Ryan RM, Deci EL. Self-determination theory and the facilitation of intrinsic motivation, social development, and well-being. Am Psycho 2000;55:68-78

28 Sandholm Grethe VH. Pædagogisk idræt - en bevægende pædagogik [in danish]. København: Corposano, 2009.

29 Bandura A. Self-Efficacy: the exercise of control. New York, NY, US: W H Freeman/Times Books/ Henry Holt \& Co, 1997: 604.

30 Hansen A, Søgaard K, Minet LR, et al. A 12-week interdisciplinary rehabilitation trial in patients with gliomas - a feasibility study. Disabil Rehabil 2018;40:1379-85.

31 Lovely MP, Miaskowski C, Dodd M. Relationship between fatigue and quality of life in patients with glioblastoma multiformae. Oncol Nurs Forum 1999;26:921-5

32 Hahn CA, Dunn RH, Logue PE, et al. Prospective study of neuropsychologic testing and quality-of-life assessment of adults with primary malignant brain tumors. Int $J$ Radiat Oncol Biol Phys 2003;55:992-9.

33 Rooney AG, Carson A, Grant R. Depression in cerebral glioma patients: a systematic review of observational studies. J Natl Cancer Inst 2011;103:61-76.

34 Murrell R. Quality of life and neurological illness: a review of the literature. Neuropsychol Rev 1999;9:209-29.

35 Graven LJ, Grant JS. Coping and health-related quality of life in individuals with heart failure: an integrative review. Heart \& Lung 2013;42:183-94.

36 Sivell S, Prout H, Hopewell-Kelly N, et al. Considerations and recommendations for conducting qualitative research interviews with palliative and end-of-life care patients in the home setting: a consensus paper. BMJ Support Palliat Care 2019;9.

37 Agger NP, Ølgod J. Mænd og kræft: anbefalinger og handlingskatalog til alle der arbejder med mandlige kræftpatienter [in danish]. København: Kræftens Bekæmpelse, 2001.

38 Lang-Rollin I, Berberich G. Psycho-oncology. Dialogues Clin Neurosci 2018;20:13-22.

39 Frederiksen M, Gundelach P, Nielsen RS. Mixed methods-forskning: principper og praksis [in danish]. Hans Reitzel, 2014. 